$\underline{\text { Original Articles }}$

\title{
Screening for mental health problems in urban preschool children - a pilot study
}

\author{
H Perera ${ }^{1}$, C Gunatunge ${ }^{2}$ \\ Sri Lanka Journal of Child Health, 2004; 33: 39-42
}

(Key words: Preschool children, mental health problems, epidemiology, urban)

\begin{abstract}
Objectives To assess prevalence and nature of mental health problems in preschool children and the feasibility and effectiveness of a screening tool for regular use by primary healthcare doctors in identifying these problems.
\end{abstract}

Setting Colombo Municipal Council Child Welfare Centre - preschool clinics.

Method Assessment tool was a semi-structured interview, which included a checklist of common symptoms of developmental, emotional and behaviour problems. Responses of the adult caregiver were recorded.

Results Data of 120 children, 36-68 months of age, were available for analysis. Mild symptoms were present in $45.5 \%$ and definite or severe symptoms in $9.9 \%$. A reliable positive correlation was found only between aggressive behaviour, disobedience and destructive behaviour $(\mathrm{r}=+0.66)$. There was low correlation between behaviour problems and eating problems and emotional symptoms $(r=+0.11)$.

Conclusion Rapid and effective screening was possible using the assessment tool, which can be used to improve recognition of mental health problem in preschoolers.

\section{Introduction}

Population studies show that prevalence of mental health problems among preschool children is about

${ }^{1}$ Senior Lecturer, Department of Psychological
Medicine, Faculty of Medicine, University of
Colombo.
${ }^{2}$ Medical Officer, Colombo Municipal Council Public
Health Services.

(Received on 10 December 2003)
$21.4 \%$, with $9.1 \%$ having severe problems ${ }^{1}$. It is also known that such problems are often dismissed as 'normal for age' or as difficulties they would 'grow out of'. Low socioeconomic status and social deprivation make children more vulnerable to develop mental health problems ${ }^{2,3,4,5}$. Other known risk factors are family conflict, physical illness and relationship difficulties ${ }^{1,6,7,8}$.

This study involves preschool children living within the city of Colombo and attending clinics conducted at a Colombo Municipal Council Child Welfare Centre (CWC). Though the stresses of urban living and related adverse socio-economic and environmental factors often challenge these children, the epidemiology of mental health problems in this group is not known. Further, an effective structure for identification of such problems within the routine health care provision, is lacking. The need for such services is demonstrated in follow up studies where it is shown that behavioural and emotional problems in preschool children are stable over time and if untreated, continue into school age and beyond ${ }^{9,10}$. Hence, effective measures for early recognition, intervention and prevention should be in place within the existing system of healthcare for these children. We aim, in this study, to test a method of screening that may be used to recognize mental health problems in these children.

\section{Objectives}

1. To assess prevalence and nature of mental health problems in preschool children attending a Colombo Municipal Council CWC.

2. To assess feasibility and effectiveness of a screening tool for regular use by primary healthcare doctors working at CWC. 


\section{Method}

The study was carried out in preschool clinics conducted at a Colombo Municipal Council CWC. Consecutive preschool children 3-5 years of age, attending $\mathrm{CWC}$ and presenting for consultation to the doctor, were selected for the study. Mental health problems were defined as emotional, behavioural and developmental problems affecting preschool age children. The assessment tool was a semi-structured interview schedule, administered by the doctor at the time child was seen for consultation. The responses of the adult caregiver, accompanying the child, were recorded. The interview schedule included the following components.

1. The demographic data of child and family.

2. A checklist of possible stressful experiences a family in the study setting may have.

3. Checklist of common physical illnesses affecting the index child.

4. A checklist of 18 common symptoms of mental health problems, responses to each symptom being given as very true $=2$, somewhat true $=1$ or not true $=0$, depending on relevance of each symptom to child concerned. Items for checklist were identified from common presenting complaints of preschool children attending hospital based mental health clinics, and those documented in published literature ${ }^{7,8,11}$. Items in checklist fall into 3 distinct symptom domains viz. behaviour problems, emotional problems and developmental problems. The test-retest reliability of the assessment checklist, assessed on a sample of 15 , was $98 \%$. Inter-rater reliability was not assessed for this pilot study, as only a single assessor was involved. As the items were obtained from clinic records of preschool children independently diagnosed with behavioural, emotional or developmental disorders, the symptom checklist was considered to have satisfactory face validity.
Epi Info Version 6 was used to evaluate frequency distribution, correlation coefficients (' $r$ ') and statistical significance ('p'). Only a correlation coefficient of 0.6 or $>$ between 2 variables was considered a reliable predictor.

\section{Results}

Data of 120 preschool children were available for analysis.

\section{Demographics of the children}

$63(52.5 \%)$ were female. Ages ranged from 36-68 months. $63(52.5 \%)$ were in the $36-47$ month group, $16(13.3 \%)$ in the $48-59$ month group and $41(34.2 \%)$ in the 60-68 month group. Mean age was 44 months (SD 0.91). 30.6\% were the only children in family, $52.1 \%$ had one or two siblings and $17.3 \%$ had more than two siblings. $57.9 \%$ of children attended preschool, $0.9 \%$ attended day care, whilst $41.2 \%$ did not attend either preschool or day care.

\section{Demographics of the parents and families}

In $92.5 \%$ cases child's father and in $89.2 \%$ the mother was living with the child. Fathers of $7.5 \%$ and mothers of $10.8 \%$ children were absent from the family and were working abroad, separated or divorced. There were no children in sample where both parents were unavailable. Mothers of $5.1 \%$ of children had not been to school, 29.6\% had attended primary school only and $10.2 \%$ had studied up to GCE Advanced Level and beyond. 52.5\% of children were living in nuclear families and $44.1 \%$ had extended families. $55.8 \%$ of families had up to 5 family members living together whilst $36.1 \%$ had 610 members. Mean number of persons living together was 6.19 .

Table I gives the distribution of individual symptoms on checklist according to severity, age and gender. Indefinite or mild symptoms were present to a maximum of $45.5 \%$ of children and definite or severe symptoms to a maximum of $9.9 \%$. 
Table 1

Distribution of individual symptoms on checklist according to severity, age and sex

\begin{tabular}{|c|c|c|c|c|c|c|c|c|}
\hline No. & Symptom & $\begin{array}{c}\text { Mild } \\
n=120 \\
(\%)\end{array}$ & $\begin{array}{c}\text { Severe } \\
n=120 \\
(\%)\end{array}$ & $\begin{array}{c}\text { At } 3 y r . \\
n=63 \\
(\%)\end{array}$ & $\begin{array}{c}\text { At } 4 y r . \\
n=16 \\
(\%)\end{array}$ & $\begin{array}{c}\text { At } 5 y r . \\
n=41 \\
(\%)\end{array}$ & $\begin{array}{c}\text { Males } \\
n=56 \\
(\%)\end{array}$ & $\begin{array}{c}\text { Females } \\
n=63 \\
(\%)\end{array}$ \\
\hline 01 & Rather solitary, plays alone & 06.6 & 0.8 & 11.1 & 06.2 & 02.4 & 07.1 & 12.7 \\
\hline 02 & $\begin{array}{l}\text { Shy, does not easily mix with } \\
\text { other children }\end{array}$ & 04.2 & 0.0 & 04.7 & 0.0 & 04.9 & 05.3 & 03.2 \\
\hline 03 & Talks less than most others of same age & 04.1 & 1.7 & 06.3 & 06.2 & 04.9 & 07.1 & 04.7 \\
\hline 04 & $\begin{array}{l}\text { Understands spoken language less than } \\
\text { most others of same age }\end{array}$ & 03.3 & 2.5 & 04.7 & 06.2 & 07.3 & 07.1 & 04.7 \\
\hline 05 & Soils self & 02.5 & 0.0 & 03.1 & 06.2 & 0.0 & 03.6 & 01.6 \\
\hline 06 & Fearful and easily scared & 08.3 & 0.0 & 11.1 & 06.2 & 04.9 & 07.1 & 09.5 \\
\hline 07 & Physically aggressive to others & 17.4 & 2.5 & 20.6 & 25.0 & 12.5 & 26.3 & 14.1 \\
\hline 08 & Disobedient & 24.0 & 2.5 & 28.5 & 31.2 & 22.5 & 24.5 & 28.1 \\
\hline 09 & Destructive, purposely breaks things & 16.5 & 1.7 & 22.2 & 16.7 & 12.5 & 24.5 & 12.5 \\
\hline 10 & Restless and unable to stay still & 15.8 & 3.3 & 20.6 & 25.0 & 15.0 & 19.3 & 18.7 \\
\hline 11 & Sleeps less than most others of same age & 02.5 & 0.0 & 01.6 & 12.5 & 0.0 & 01.8 & 03.2 \\
\hline 12 & Refuses food & 45.5 & 5.8 & 60.1 & 43.7 & 42.5 & 43.8 & 59.3 \\
\hline 13 & Eats only selective food & 43.0 & 8.3 & 67.1 & 43.7 & 47.5 & 43.8 & 57.8 \\
\hline 14 & Has nightmares & 02.5 & 0.8 & 04.7 & 06.2 & 0.0 & 03.6 & 03.2 \\
\hline 15 & Head banging and temper tantrums & 07.4 & 1.7 & 09.5 & 12.5 & 05.0 & 10.5 & 08.1 \\
\hline 16 & $\begin{array}{l}\text { Often complains of various } \\
\text { physical symptoms }\end{array}$ & 132 & 00 & 143 & 062 & 119 & 087 & 17.1 \\
\hline 17 & Unhappy/tearful & 02.5 & 0.0 & 04.7 & 0.0 & 0.0 & 03.6 & 01.6 \\
\hline 18 & Cruel to animals & 04.1 & 0.0 & 03.1 & 06.2 & 04.9 & 05.3 & 03.2 \\
\hline
\end{tabular}

There was a reliable correlation between aggressive behaviour, disobedience and destructive behaviour $(\mathrm{r}=+0.66)$.

There was no reliable correlation between behaviour problems and eating problems and emotional symptoms $(\mathrm{r}=+0.11)$

There was no reliable correlation between speech delay and behaviour problems $(\mathrm{r}=+0.19)$.

There was no reliable correlation between solitary behaviour and shyness $(r=+0.49)$.

There was no reliable correlation of poor skills with speech and poor language comprehension $(r=+0.53)$

There was no reliable correlation between refusal of food and other symptoms ( $\mathrm{r}=0.17$ or less).

\section{Stressful family situations}

$63.6 \%$ did not report stressful situations at home. Among the rest, financial difficulties and excessive alcohol consumption in a family member was reported as the commonest causes of stress.

\section{Illness in the child}

$76.8 \%$ did not report any physical illness. In the rest, illnesses related to the respiratory system were the commonest and were reported in $12.4 \%$ of children.

There was no statistically significant association found on cross tabulation, between symptoms of mental health problems and stress at home or physical illness in child $(\mathrm{p}>0.05)$. Statistically significant association was not found between behaviour problems and family size, mother's educational level or attendance/non-attendance at preschool $(\mathrm{p}>0.05)$.

\section{Discussion}

The study population of preschool children represents most others who attend CWCs in Colombo, in their economic and sociocultural mix. Hence, it may be reasonable to extend the results of this study to these geographical limits. Rapid administration of the screening schedule ( 8 minutes) was possible while covering a substantial area of inquiry about possible mental health problems in developmental, emotional and behavioural domains, and their social correlates. 
Since the objective of the screening tool is to improve recognition of mental health problems, testing it across different social and ethnic subgroups might allow its use in a wider primary healthcare setting.

A two stage screening process for identification of cases was not considered in this study. This was because a doctor directly administered the checklist instead of parents being involved in an initial selfassessment. However, a two stage screening involving a primary healthcare doctor and a mental health professional would further validate the checklist and may avoid inclusion of false positives. A further positive validity of the assessment is shown by its ability to detect known symptom clusters. For example, a reliable positive correlation is shown between aggressive, destructive, disobedient and restless behaviour, which is further supported by their low correlation with emotional symptoms.

Mild disruptive behaviour was seen in about $17 \%$ of children, which is known to represent a temperamental quality rather than a disorder ${ }^{12,13,14}$. However, such temperaments should be identified as they are vulnerability factors for both emotional and behavioural disorders in preschool children when under stress ${ }^{15,16,17}$. In addition, the persistence of these behaviours is apparent, as there is only a $9.7 \%$ reduction from 36-60 months of age. Feeding related problems were reported by over $50 \%$ of mothers and were consistently high through all age groups. Moderate to severe problems related to food intake is reported in $12 \%$ of preschoolers ${ }^{11}$. However, a very low correlation between eating behaviours and other symptoms $(\mathrm{r}=0.11)$ seen in this study indicates that the former is a stand-alone problem in these children. Hence, biased reporting by mothers due to culturally based preoccupation with feeding is a more likely explanation for the high prevalence, than a relationship to mental health.

\section{Conclusion}

Screening is necessary to detect mental health problems in preschool children, as parents are unlikely to voluntarily report them in contrast to physical problems. The results of this study show the need for a screening process in place in the CWCs and the training of doctors in basic mental health care for young children.

\section{References}

1. Lavigne J V, Gibbons R D, Christoffel K K, Arend $\mathrm{R}$, et al. Prevalence rates and correlates of psychiatric disorders among preschool children. Journal of the American Academy of Child and Adolescent Psychiatry 1996; 35: 204-14.

2. Adam C D, Hillman N, Gaydos G R. Behavioural difficulties in toddlers: impact of socio-cultural and biological risk factors. Journal of Clinical Child Psychology 1994; 23: 373-81.

3. Shaw D S, Emery R E. Chronic family adversity and school aged children's adjustment. Journal of the American Academy of Child and Adolescent Psychiatry 1988; 27: 200-6.

4. Thompson M J J, Stevenson J, Sonuga-Barke E, Nott P, et al. Mental health of preschool children and their mothers in a mixed urban/rural population - I. Prevalence and ecological factors. The British Journal of Psychiatry 1996; 168: 1620.

5. Quinton D. Urbanism and mental health. Journal of Child Psychology and Psychiatry 1988; 29: 11-20.

6. Prior M, White J, Merrigan C, Adler R. Preschool behaviour problems in a multicultural Australian urban area. Journal of Pediatrics and Child Health 1998; 34: 164-9.

7. Keenan K, Shaw D S, Walsh B, Delliquadri E, Giovannelli J. DSM III R disorders in preschool children from low income families. Journal of the American Academy of Child and Adolescent Psychiatry 1997; 36: 620-7.

8. Pavuluri M N, Luk S L. Pattern of preschool behaviour problems in New Zealand, using Behaviour Check List. Journal of Pediatrics and Child Health 1996; 32: 132-7.

9. Lerner J A, Inui T S, Trupin E W, Douglas E. Preschool behaviour can predict future psychiatric disorders. Journal of the American Academy of Child and Adolescent Psychiatry 1985; 24: 42-8. 
10. Campbell S B, Ewing L J, Breaux A, Szumowski E K. Parent referred problem three-year-olds: follow up at school entry. Journal of Child Psychology and Psychiatry 1986; 27: 473-88.

11. Le Couteur A. Clinical syndromes in early childhood. In: Black D. Cottrell D, editors. Seminars in Child and Adolescent psychiatry. London; Gaskell,1993.

12. Earles P, Jung K G. Temperament and home environment characteristics as causal factors in the early development of childhood psychopathology. American Academy of Child and Adolescent Psychiatry 1987; 26: 491-8.

13. Petit G S, Bates J E. Family interaction patterns and children's behaviour problems from infancy to 4 years. Developmental Psychology 1989; 25: 413-20.
14. Wolfson J, Fields J H, Rose S A. Symptoms, temperament, resiliency and control in anxietydisordered preschool children. American Academy of Child and Adolescent Psychiatry 1987; 26: 16-22.

15. Carey W B. Temperament risk factors in children: a conference report. Journal of Developmental and Behavioral Pediatrics 1990; 11: 28-34.

16. Rutter M. Temperament, personality and personality disorders. British Journal of Psychiatry 1987; 150: 443-58.

17. Tschann J M, Kaiser P, Chesney M, Alkon A, Boyce T. Resilience and vulnerability among preschool children: family functioning, temperament and behaviour problems. Journal of the American Academy of Child and Adolescent Psychiatry 1996; 35: 184-92. 
